\title{
REVIEW
}

\section{Gas plasmas and plasma modified materials in medicine}

\author{
Sadiqali Cheruthazhekatt ${ }^{1}$, Mirko Černák ${ }^{2}$, Pavel Slavíček ${ }^{2}$, Josef Havel ${ }^{1,2}$ \\ ${ }^{1}$ Department of Chemistry, Faculty of Science, Brno, Czech Republic \\ ${ }^{2}$ Department of Physical Electronics, Faculty of Science, Brno, Czech Republic
}

Received $8^{\text {th }}$ February 2010.

Revised $25^{\text {th }}$ March 2010.

Published online $19^{\text {th }}$ April 2010.

\begin{abstract}
Summary
The applications of gas plasma and plasma modified materials in the emerging fields of medicine such as dentistry, drug delivery, and tissue engineering are reviewed. Plasma sterilization of both living and nonliving objects is safe, fast and efficient; for example plasma sterilization of medical equipment quickly removes microorganisms with no damage to the tiny delicate parts of the equipment and in dentistry it offers a non-toxic, painless bacterial inactivation of tissues from a dental cavity. Devices that generate plasma inside the root canal of a tooth give better killing efficiency against bacteria without causing any harm to the surrounding tissues. Plasma modified materials fulfill the requirements for bioactivity in medicine; for example, the inclusion of antimicrobial agents (metal nano particles, antimicrobial peptides, enzymes, etc.) in plasma modified materials (polymeric, metallic, etc.) alters them to produce superior antibacterial biomedical devices with a longer active life. Thin polymer films or coating on surfaces with different plasma processes improves the adherence, controlled loading and release of drug molecules. Surface functionalization by plasma treatment stimulates cell adhesion, cell growth and the spread of tissue development. Plasma applications are already contributing significantly to the changing face of medicine and future trends are discussed in this paper.
\end{abstract}

Key words: plasma; sterilization; dentistry; surface functionalization; drug delivery; tissue engineering

\author{
Abbreviations \\ DBD, dielectric barrier discharge \\ B. cereus, Bacillus cereus \\ E. coli, Escherichia coli \\ NPs, nanoparticles \\ PA, porous alumina \\ PAA, polyacrylic acid \\ P. aeruginosa, Pseudomonas aeruginosa \\ $\mathrm{PE}$, polyethylene
}

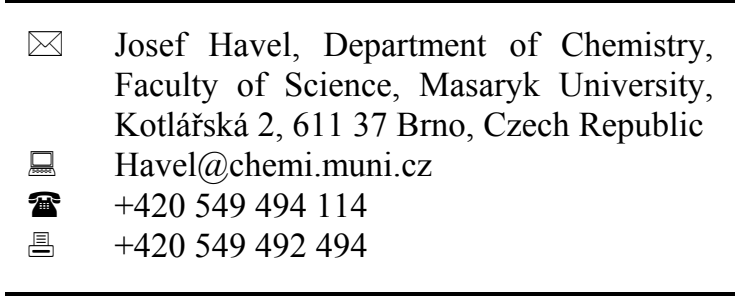

PEG, poly(ethylene glycol)

PHBV, poly(3-hydroxybutyric acidco-3-hydroxyvaleric acid)

PIII, plasma immersion and ion implantation

$\mathrm{PP}$, polypropylene

PSDVB, polystyrene-divinylbenzene

$\mathrm{PU}$, polyurethanes

$\mathrm{RF}$, radio frequency

S. aureus, Staphylococcus aureus

S. mutans, Streptococcus mutans

\section{INTRODUCTION}

Plasma is considered as the fourth state of matter and it is the most abundant state in the universe. It exists in a variety of forms among which is 'fire', known for millions of years, since the early stone age. Plasma is not a human invention, and is present in nature, as fire 
in the sun, stars, in the tails of comets and as flashes of lightning (Conrads and Schmidt 2000). In medicine and biology 'plasma' refers to the non-cellular fluid component of blood. The term was introduced into physics by Irving Langmuir in 1928, because it resembles the ionic liquids in biology and medicine.

The number of applications of plasma technology in many fields including microelectronics, metallurgy, polymer engineering, and biomedical engineering, is growing rapidly. One of the advantages of this technology is that surface properties such as hardness, corrosion resistance and other chemical and physical properties can be selectively modified without affecting the bulk characteristics of the materials. The use of synthetic materials in biomedical applications has increased dramatically during the past few decades. However some synthetic biomaterials, for example polymeric implants, can, in biosystems, cause problems, such as microbial growth and/or adsorption of bioorganisms. The simple addition or deposition of bioactive molecules to such materials can offer less stability and uniformity than covalently bonded species. In comparison with other methods for surface modification (layer by layer deposition, dipping, etc.) plasma surface modification offers a shorter and more economical method for the covalent attachment of bioactive molecules to the substrate without obstructing the bulk properties (Chu et al. 2002, Oehr 2003). Thus plasma technology has great importance in the development of new biomaterials. In medicine direct plasma treatment for sterilization, deactivating pathogens, blood clotting, wound healing, cancer treatment, etc. is more effective than any other method. Thus, plasma and plasma modified materials play an important role in our daily live, making it more convenient and healthier.

Several reviews of the biomedical application of plasma and plasma treated materials have been published (Fridman et al. 2008, Gomathi et al. 2008, Laroussi 2008, Desmet et al. 2009), but to date, none gives an overview of modern applications of plasma and plasma modified materials in medicine; the aim of this review is therefore to present a survey of recent advances of plasma and plasma modified materials in this field.

\section{PLASMA FORM OF MATTER AND METHODS FOR GENERATION}

On the application of sufficient heat, a solid material transforms firstly into a liquid and then. at a higher temperature, into a gas. As the energy supplied is increased, the electrons receive sufficient energy to separate from the atoms or molecules of gas and become electrically conductive. In this way gas undergoes a phase transition to a partially or completely ionized gas, called the plasma state. Fig. 1 illustrates the phase transformations of matter by changes in the energy of the system under processes such as melting, vaporization, ionization, etc.

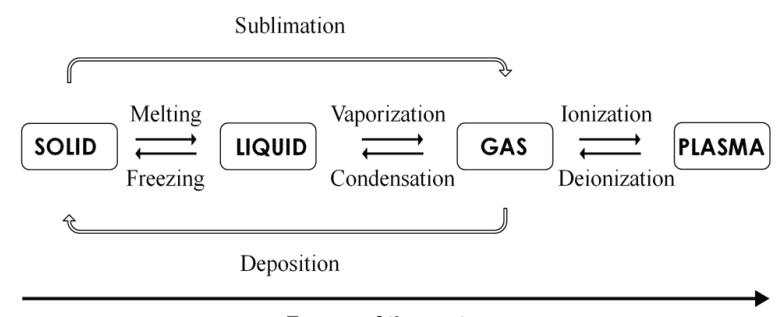

Energy of the system

Fig. 1. Different states of matter.

Plasma consists of a mixture of positively and negatively charged ions, electrons and neutral species (atoms, molecules). It can be divided into two main categories; hot plasma (near-equilibrium plasma) and cold plasma (non-equilibrium plasma). Hot plasma consists of very high temperature particles and they are close to the maximal degree of ionization. Cold plasma is composed of low temperature particles and relatively high temperature electrons and they have a low degree of ionization (Tendero et al. 2006). Cold plasma can be further subdivided into low pressure and atmospheric pressure cold plasma. Atmospheric pressure cold plasma is the basis of one of the most promising methods of achieving a more flexible, reliable, less expensive and continuous method of surface modification (Bogaerts et al. 2002). Different forms of energy (thermal, electric current, electromagnetic radiations, light from a laser, etc.) are used to create the plasma regardless of the nature of the energy source. Depending on the type of energy supplied and the amount of energy transferred to the plasma, the properties of the plasma change in terms of electron density or temperature (Braithwaite 2000). In common, man made, plasma, electrical energy is usually injected into a system in a continuous manner in order to avoid stoppage of the plasma discharge. Plasma is most commonly produced by passing an electric current through the gas. Different frequencies of power sources - direct current, alternating current, low frequency, radio frequency, microwave, etc. are used for the generation of discharges such as atmospheric and low pressure glow discharge, corona, magnetron and dielectric barrier discharge (DBD) (Conrads and Schmidt 2000, Denes and Manolache 
2004). An example of a high frequency plasma jet pencil is given in Fig. 2 (Klíma et al. 1998, 2003, 2005) and plasma generated by a surface coplanar barrier discharge in ambient air atmosphere is given in Fig. 3. Plasma parameters must be designed specifically for a given application a splasma sources have their own peculiarities, advantages, and disadvantages. The selection of a plasma source and design for the production of novel material is a great challenge for scientists and industry.
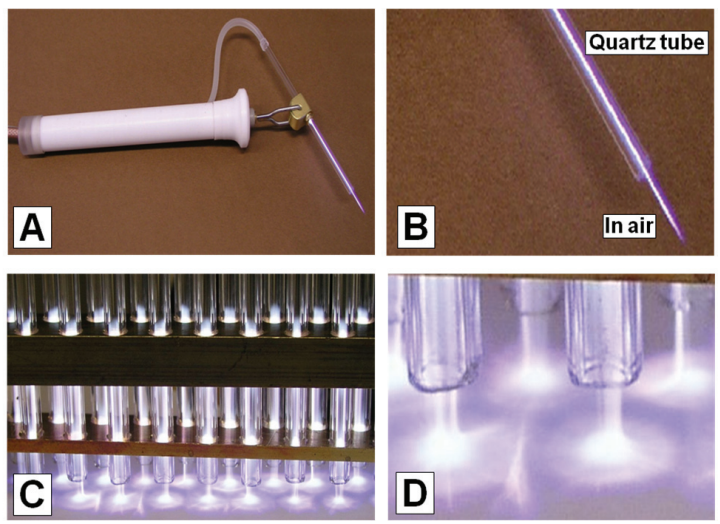

Fig. 2. (A) Plasma pencil device. (B) Magnified plasma pencil torch glowing in a quartz tube and in air. (C) Multi jet system. (D) Magnified multi jests modifying the surface. Photo: M. Klima (reproduced with permission).
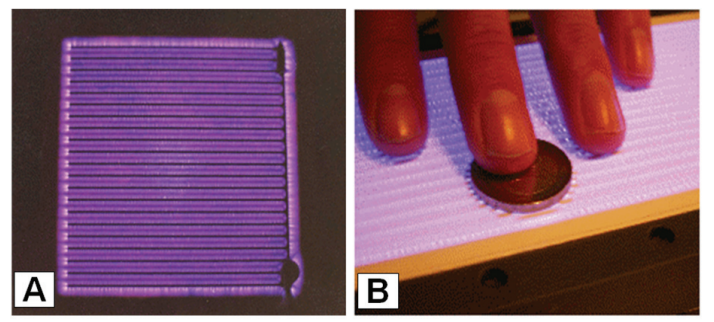

Fig. 3. Scheme of barrier discharge generation. (A) Plasma of surface barrier discharge and (B) Illustration of safety of the surface coplanar barrier discharge burning in ambient air atmosphere.

\section{PLASMA TREATMENT IN MEDICINE}

Heat and high temperature (steam, hot metal objects) have been used in medicine for a significant length of time: in tissue removal, blood clotting, wound healing and for the disinfection of both living and non-living biomedical articles. Direct contact with hot metal will affect the surrounding tissues in living organisms by tissue adhesion, restarting of bleeding, charring of the neighbouring tissues and causes damage to heat sensitive biomedical articles. Treatment with low temperature plasma provides an alternative method of avoiding the difficulties associated with this ancient method (Hayashi et al. 2006, Fridman et al. 2008), because the ions and the neutral species in low temperature plasma are relatively cold and do not cause any thermal damage to articles which come in contact with the plasma. This non-thermal behavior recommends the use of gas plasma for the treatment of heat sensitive materials including biological matter, such as cells and tissues (Laroussi 2005). In recent years, non-thermal atmospheric plasma effects have been developed to extend the plasma treatment of living tissue. These can be selective in achieving a desired result for some living matter, while having little or no effect on the surrounding tissue (Fridman et al. 2008), and have found application in low heat surface modification of polymers (Gomathi et al. 2008), clinical instrument sterilization, tissue engineering and dental cavity treatment (Shenton and Stevens 2001, Denes and Manolache 2004, Laroussi 2005). Many different types of plasma devices including plasma pencils, radio frequency plasma needles, direct current plasma brushes and plasma jets have been developed for non-thermal atmospheric pressure plasma generation (Laroussi et al. 2008, Nie et al. 2009). A brief overview of gas plasma applications in medicine is given in Fig. 4.

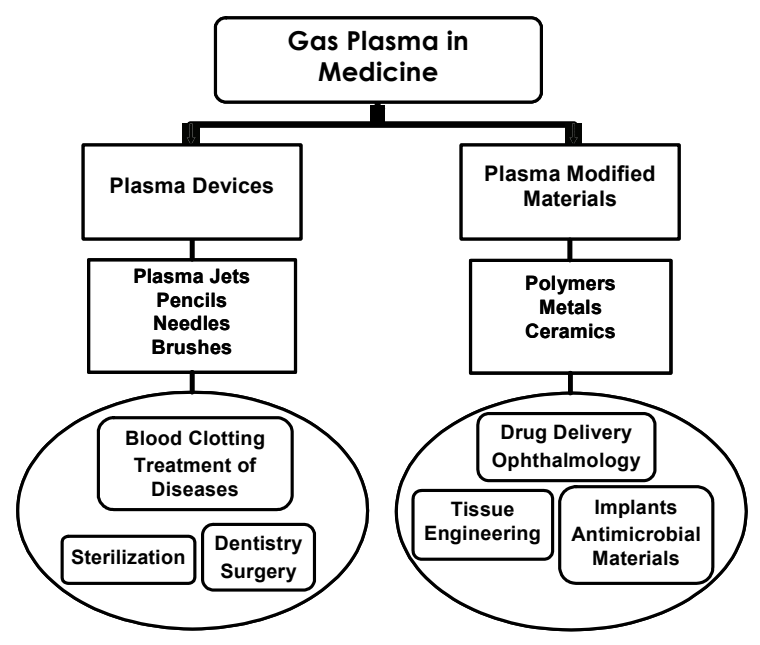

Fig. 4. Gas plasma uses in medicine.

\section{Plasma sterilization}

Plasma sterilization is a well established technology in medicine. Plasma, in the form of fire, was used for sterilization thousands of years ago. The sterilization 
of living objects, such as human, animal, and plant tissues is of much interest in medicine (Crow and Smith 1995). Plasma sterilization works at the atomic/molecular level and therefore it helps to reach all surfaces, including the interior parts of medical equipment (catheters, needles, syringes, etc.) and other regions which are not accessible to fluid disinfectants (Fridman et al. 2007). It has several advantages (see Fig. 5) over commonly used sterilization methods such as heat, chemical solutions, or gas and radiation bombardment which cause thermal, chemical, or irradiation damage to both living and non-living objects. The parametric study of plasma for sterilization is of importance in understanding and controlling the deactivation of microbes, because the main sterilizing factors are strongly dependent on the plasma source type and/or the plasma characteristics. Nowadays non-thermal atmospheric pressure plasma is more frequently used for the sterilization of both living and non-living materials (Lerouge et al. 2001, Trompeter et al. 2002, Xingmin et al. 2006, Fridman et al. 2008, Moreau et al. 2008).

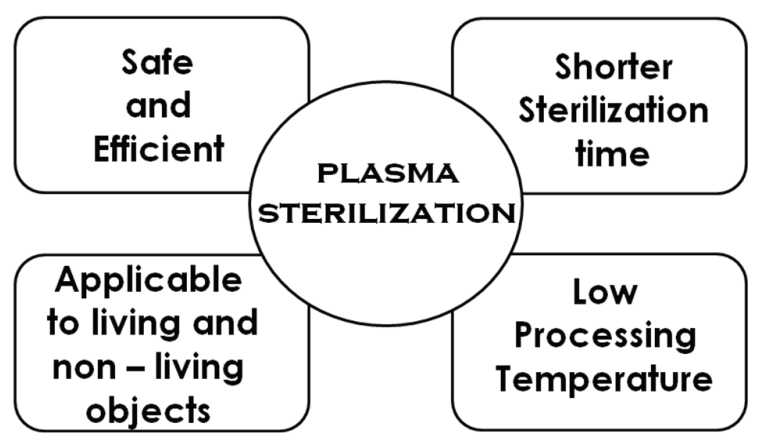

Fig. 5. Some advantages of plasma sterilization.

\section{Sterilization of living materials}

Several types of plasma device have been reported for the sterilization of living animal and human tissues. An electrically safe DBD plasma with a floating electrode set up has been reported for the sterilization of living tissue. This method provides complete tissue sterilization within seconds, with no damage to skin samples (Fridman et al. 2006). Recently a new DBD non-thermal plasma at atmospheric pressure with conical geometry structured electrodes was developed for evaluating the bactericidal effect against Pseudomonas aeruginosa ( $P$. aeruginosa), Bacillus cereus (B. cereus) and Escherichia coli (E. coli) bacteria. The complete removal of these microorganisms was effected within an exposure time of $10 \mathrm{~min}$ for P. aeruginosa, and $15 \mathrm{~min}$ for E. coli and B. cereus, respectively (Sohbatzadeh et al. 2009). Low power radio frequency (RF) plasma at atmospheric pressure with a helium flow is used for the no damaging sterilization of living tissues. This plasma has the capacity to kill different kinds of bacteria: E. coli, P. aeruginosa and Staphylococcus aureus ( $S$. aureus) with a decimal reduction time of 1-2 minutes, while preserving the living cells of the substrate (Martines et al. 2009). Gweon et al. (2009) studied the sterilization mechanisms and the major sterilization factors of RF plasma, with $E$. coli as the target. They found that sterilization is more effective (up to $40 \%$ ) with $0.15 \%$ oxygen added to the helium gas supply. Moon et al. (2009), generated a relatively large area $(110 \mathrm{~mm} \times 25 \mathrm{~mm})$ of RF discharges with low current and low gas temperature at atmospheric pressure to carry out treatment on living tissue. They investigated possible electrical and thermal damage and also the sterilization efficiency for living cell treatment which was tested with microorganisms inoculated on pork and human skin surfaces.

\section{Sterilization of non-living materials}

The sterilization of medical equipment is an important procedure for disinfection in hospitals, and a number of medical plasma sterilizer devices have been introduced (Griffiths 1993, Herrmann et al. 1999, Lin et al. 1999, Montie et al. 2000, Gaunt et al. 2006, Laroussi et al. 2006).

The removal of protein residues from surgical instruments is quite difficult and commonly used sterilization and decontamination techniques can cause major damage to the objects treated. Kylián et al. (2008) developed a low pressure inductively coupled $\left(\mathrm{Ar} / \mathrm{O}_{2}\right.$ mixture) plasma discharge for the removal of model proteins from different substrate materials ranging from metallic surfaces to polymeric materials. Ar/ $\mathrm{O}_{2}$ mixture represents a favorable option compared to the discharges sustained in other gases or gas mixtures, since it allows for the fast elimination of proteins and killing of bacterial spores. Moreover, the application of this mixture overcomes the environmental and safety drawbacks of mixtures containing fluorine which is found to be capable of sterilizing and etching organic materials.

It is important to find appropriate plasma sterilization conditions for modern polymeric medical devices, because under some conditions sterilization will destroy the surfaces by degradation of the chains and produce some low molecular volatiles. Halfmann et al. (2007) introduced double inductively coupled low pressure plasma for sterilization of three dimensional biomedical materials. The short 
treatment time and low temperature allow for the sterilization of heat sensitive materials such as ultra high molecular weight polyethylene (PE) and polyvinyl chloride (PVC). In the experimental study of Miao and Jierong (2009), the germicidal effect of E. coli on the surface of medical PVC in remote oxygen plasma and the effective inactivation of the E. coli by this plasma was observed. Compared with direct oxygen plasma sterilization, remote plasma can enhance the hydrophilic property and limits the degradation of the PVC surface.

\section{Plasma in dentistry}

A number of methods, such as mechanical drilling, laser techniques and chemical reagents have been employed for the cleaning and disinfection of the tissue in dental cavities or in root canals. However, most of these methods have disadvantages such as heating, the destruction of healthy tissues, and undesirable side effects including a disagreeable taste and staining by chemotherapeutic agents such as chlorhexidine (Goree et al. 2006). Plasma bacterial inactivation of tissues in a dental cavity or in a root canal is of importance and a tissue saving method in dentistry. The exposure of enamel to the plasma is painless and the heating of the pulp is tolerable. Furthermore, plasma is non-toxic and it does not cause damage to the mineralized matrix of the tooth.

Several types of nonthermal atmospheric plasma devices have been used for dental treatment (Sladek et al. 2004). A low power, millimeter sized, atmospheric pressure glow discharge plasma needle was developed to kill Streptococcus mutans (S. mutans) which is the main microorganism causing dental caries. This plasma can effectively kill the bacteria with a treatment time of ten seconds within a solid circle of $5 \mathrm{~mm}$ diameter, demonstrating its site specific treatment capabilities (Goree et al. 2006). Atmospheric pressure DBD plasma needles with a funnel shaped nozzle were used for the inactivation of $S$. mutans. Oxygen was injected downstream in the plasma afterglow region through a powered steel tube (Zhang et al. 2009). Jiang et al. (2009), introduced a safe and novel technique for endodontic disinfection with a hollow electrode based, $100 \mathrm{~ns}$ pulsed plasma dental probe. It generates a room temperature, tapered cylindrical plasma plume in ambient atmosphere. The plasma plume causes minimal heating of biological materials and is safe to touch with bare hands without causing a burning sensation or pain. Greater sterilization depth and surface coverage were achieved by optimizing the width and length of the plasma plume. A non-thermal atmospheric pressure helium plasma jet device was developed to enhance the tooth bleaching effect of hydrogen peroxide. The combination of the plasma with hydrogen peroxide improves the bleaching efficacy by a factor of three compared to sterilization by hydrogen peroxide alone (Lee et al. 2009).

Due to the narrow channel shape geometry of the root canal of a tooth, the plasma generated by some devices is not efficient in delivering reactive agents into the root canal for disinfection. Therefore, to have a better killing efficacy, plasma has to be generated inside the root canal. Recently Lu et al. (2009), constructed a cold plasma jet device which can generate plasma inside the root canal and which efficiently kills Enterococcus faecalis (one of the main types of bacteria causing failure of the root canal) within several minutes.

\section{PLASMA MODIFIED MATERIALS IN MEDICINE}

The surface properties of materials play an essential role in determining their biocompatibility, strongly influence their biological response and determine their long term performance in vivo (Chu et al. 2002). Many synthetic biomaterials such as metals, alloys, ceramics, polymers and composites have a different environment from the natural environment consisting of neighbouring cells or extra cellular matrix components. So it is important to design biomaterials with the right surface properties, especially chemical binding properties to achieve the biocompatibility of artificial biomaterial surfaces. For surface modification in the medical field, very thin layers with a thickness of some ten to hundred nanometers are mainly required (Favia et al. 2008). The treatment of the surfaces of materials with non-thermal plasma can lead to surface activation and functionalization. This creates unique surface properties often unobtainable with conventional, solvent based chemical methods. Thus plasma surface modification can improve biocompatibility and biofunctionality. Appropriate selection of the plasma source enables the introduction of diverse functional groups on the target surface to improve biocompatibility or to allow subsequent covalent immobilization of various bioactive molecules (Gupta and Anjum 2003, Oehr 2003, Denes and Manolache 2004). Polymers are common medical materials because of their superior properties such as easy processing, ductility, impact load damping and excellent biocomparability (Gomathi et al. 2008). A list of polymeric and metallic plasma treated biomaterials and their uses is given in Table 1. 
Cheruthazhekatt et al.: Gas plasmas and plasma modified materials in medicine

Table 1. Plasma modified materials and their applications.

\begin{tabular}{ll}
\hline Plasma modified materials & Applications \\
\hline Polymers & \\
Polyethylene & \\
$\begin{array}{l}\text { Polypropylene } \\
\text { Polyvinylchloride }\end{array}$ & Catheters, anti-microbial coatings, implants \\
Polyurethanes & \\
Polytetrafluoroethylene & Implants, vascular grafts \\
$\begin{array}{l}\text { Poly(methyl methacrylate) } \\
\text { Silicone rubber }\end{array}$ & Contact lenses, artificial corneas \\
$\begin{array}{l}\text { Poly(ethylene terephthalate) } \\
\text { Polystyrene }\end{array}$ & Implants, tissue culture dishes \\
$\begin{array}{l}\text { Polylactic acid } \\
\text { Polyglycolic acid }\end{array}$ & Sutures, drug delivery matrix \\
$\begin{array}{l}\text { Metals and alloys } \\
\text { Ti }\end{array}$ & \\
$\begin{array}{l}\text { Ti-Ni alloys } \\
\text { Co-Cr alloys }\end{array}$ & Implants \\
Steel & Stents \\
\hline
\end{tabular}

\section{Types of plasma surface modification processes}

A number of plasma processes have been developed to attain specific surface properties for biomaterials and some are listed below

a) surface functionalization by gas plasma $\left(\mathrm{O}_{2}, \mathrm{CO}_{2}\right.$, $\mathrm{N}_{2}, \mathrm{NH}_{3}$, etc.);

b) formation of thin films by plasma polymerization;

c) inclusion of metal ions in the surface by plasma induced ion implantation.

Analytical techniques such as optical microscopy, 3D laser profiling, scanning electron microscopy, atomic force microscopy, contact angle, X-Ray photoelectron spectroscopy, static time of flight secondary ion mass spectrometry and dynamic secondary ion mass spectrometry have been used to characterize the surface properties of plasma modified materials.

\section{Antimicrobial materials}

The biomaterials used for the treatment of diseases and for implants must possess good antimicrobial properties. So it is important to improve the antibacterial properties of such materials by the incorporation of antimicrobial agents in, or by the application of surface coatings to the materials used.
The antimicrobial properties of metals and metal ions (silver, copper, etc.) have been well known since ancient times. Nowadays, metal nanoparticles (NPs) are widely employed to improve the antimicrobial activity of many synthetic biomaterials (Weir et al. 2008). This bactericidal effect of metal NPs has been attributed to their small size and high surface to volume ratio which allow them to interact closely with microbial membranes. Metal NPs with bactericidal activity can be immobilized and coated onto surfaces which may find application in medical instruments and devices (Kim et al. 2007, Ruparelia et al. 2008). Plasma processes such as plasma sputtering, plasma induced ion implantation and plasma enhanced chemical vapor deposition among others, are relatively simple and efficient methods for the incorporation of such agents. In this way the antimicrobial properties of the biomaterials made from metals, polymers, and other materials have been improved.

\section{Metallic biomaterials}

Copper is known to be active against bacteria and fungi (Silver and Phung 1996, Noyce et al. 2006). An antibacterial nanocomposite of copper containing organosilicon thin films, has been successfully 
synthesized on stainless steel using a mixed plasma enhanced chemical vapor deposition-sputtering deposition technique. The antimicrobial properties were evaluated with a solution containing $E$. coli microorganisms for $24 \mathrm{~h}$, the $E$. coli concentration decreased to the minimal detectable value. The process parameters were optimized to control the quantity of incorporated copper in the layer (Daniel et al. 2009).

Silver ions are widely used as a bactericide in catheters, burn wounds and dental work. The incorporation of silver into implants is a most promising method in reducing the infection rate, while exhibiting low toxicity towards cells and tissues. Some harmful effects of silver nanoparticles and their toxicity for human health have been reviewed (Panyala et al. 2008). The inhibitory effect of silver on bacteria is generally believed to be caused by silver reacting with thiol groups in protein which induce the inactivation of the bacterial proteins (Rai et al. 2009, Sharma et al. 2009). A plasma sprayed nano-titania/silver coating was deposited on titanium substrates for the prevention of bacterial infections. The experimental results confirmed that the plasma sprayed nano-titania/silver coating has good bioactivity, cytocompatibility and antibacterial properties, which makes it a promising application against postoperative infections in the replacement of hard tissues ( $\mathrm{Li}$ et al. 2009). The inclusion of silver into the chemical treatment of the surface of vacuum plasma sprayed titanium coatings plays an important role in inhibiting the proliferation of bacteria. The treated titanium coatings exhibit a prominent antibacterial effect against $E$. coli, $P$. aeruginosa and $S$. aureus (Chen et al. 2009b). The antibacterial properties of doped silver on biocompatible silica based glass have also been studied. Firstly the glass powders were coated on titanium alloy and stainless steel substrates by a plasma spray process in air. In vitro test results showed an antimicrobial action against tested bacteria without disturbance of the biocompatibility of the glass (Miola et al. 2009). Stainless steel dental device plates were modified by the plasma based fluorine and silver ion implantation-deposition method. Due to the presence of both fluoride and silver ions, the brushing abrasion resistance of the deposited or mixing layer was improved and the hydrophobic properties remained even after brushing with a toothbrush. This simultaneous fluoride and silver ion implantation-deposition could provide a possible antimicrobial property to medical and dental devices (Shinonaga and Arita 2009).

A nanolayer biofilm of polyacrylic acid (PAA) was uniformly coated on the surface of magnetic nickel NPs using a dielectric barrier discharge glow plasma fluidized bed. The PAA acting as an adhesion layer was used to immobilize a certain concentration of antimicrobial peptide (LL-37) to kill the bacteria E. coli. The results indicated that the modified nickel NPs immobilizing a certain concentration of LL-37 could kill the bacteria effectively (Chen et al. 2009a).

\section{Polymeric biomaterials}

Medical polymers are widely used in biomedical applications because of their excellent mechanical and biological properties. However, the infection in medical polymers is a major clinical complication. Recently plasma surface modification techniques have been employed in the development of anti-infective medical polymers for the biomedical industry (Sodhi et al. 2001, Ji et al. 2007).

A comparative study has been carried out on single and dual copper plasma immersion and ion implantation (PIII) to produce an antibacterial surface on polyethylene (PE). Compared with the single copper PIII process, the dual plasma implantation process $\left(\mathrm{Cu} / \mathrm{N}_{2}\right.$ PIII) can better regulate the copper release rate and improve the long term antibacterial properties of PE against E. coli and S. aureus (Zhang et al. 2007). The improved antimicrobial activity of plasma treated PE films after chemical immobilization of an antimicrobial enzyme (lysozyme) has also been investigated. Plasma conditions and enzyme solution concentrations were optimized for the effective immobilization on the PE surface (Conte et al. 2008). A tunable antimicrobial polypropylene (PP) surface with a controllable strength against Pseudomonas putida and S. aureus has been recently reported. Microwave plasma reaction in the presence of maleic anhydride results in the formation of acid groups on the surface of PP. This modification of the plasma surface helps the attachment of antibiotics such as penicillin V (PEN) and gentamicin (GEN) to the modified PP surface through the reaction of the acid group on the PP surface and polyethylene glycol (PEG), diglycidyl PEG respectively (Aumsuwan et al. 2009).

\section{Drug delivery}

Plasma surface modification provides sufficient adherence to metallic and polymeric materials for the binding of drug molecules. The bioabsorbable materials can act as drug carriers by controlling the release rate of the drug initially loaded in an application for drug delivery systems. Fig. 6 shows the schematic illustration of a drug molecule grafting on an $\mathrm{O}_{2}$ plasma treated substrate. 


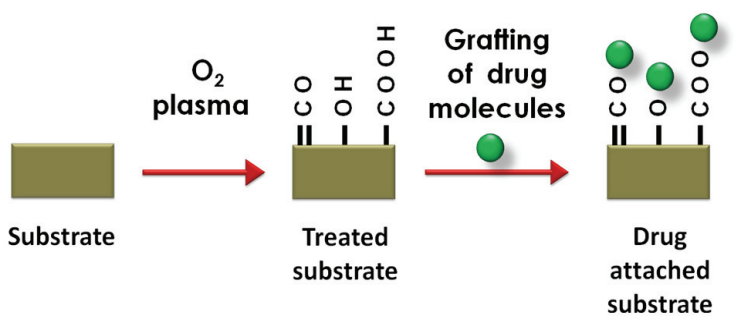

Fig. 6. Incorporation of drug molecules to plasma treated substrate for drug delivery ( Drug molecule).

Nanoporous membranes have attracted considerable interest for application in drug delivery. The deposition of heptylamine plasma polymer coatings onto porous alumina (PA) membranes has been investigated with the aim of adjusting the surface chemistry and the pore size of the membranes. The structural (pore size) properties of PA membranes can be altered systematically by adjusting the deposition time during the polymerization process. The resultant PA membranes with active amino groups and controlled pore size are applicable for molecular separation and drug delivery (Losic et al. 2008). The polylactic acid ultrasound contrast agent has significant importance in ultrasound imaging and eventually in drug treatment for cancer. It has an additional advantage, because ultrasound in drug delivery may induce cavitations, increase cell membrane permeability and facilitate drug release. Plasma surface modification improves drug loading for ultrasound-triggered drug delivery. Plasma treatment appears to both sterilize and beneficially modify the agent for increased doxorubicin adsorption (Eisenbrey et al. 2009). The macroporous structure of polystyrene-divinylbenzene (PS-DVB) solid foams materials with high pore volume makes them interesting for the design of new drug delivery systems. The wettability of the highly hydrophobic PS-DVB films was improved by a short post discharge plasma treatment with different gases with a view to opening new possibilities for the absorption of hydrophilic compounds (Canal et al. 2009). The surface functionalization of $\mathrm{TiO}_{2}$ nanotubes by plasma polymerization generates a thin and chemically reactive polymer film rich in amine groups on top of the substrate surface. The tailoring of surface functionalities on nanotube surfaces has potential for significantly improving the properties of this attractive biomaterial and promoting the development of new biomedical devices such as drug eluting medical implants with multiple functions (orthopedic implants, dental, coronary stents). This will provide an elegant route to the prevention of infection, clotting control or to a decrease in inflammation as a result of these implants (Vasilev et al. 2010).

\section{Tissue engineering}

Artificial materials are of growing importance in medicine and biology. A modern scientific interdisciplinary field known as tissue engineering has been developed to design artificial biocompatible materials to substitute irreversibly damaged tissues and organs. Cells can sense the physical properties and chemical composition of these materials and regulate their behavior accordingly (Bačáková et al. 2004). Cell affinity is the most important factor to be considered when biodegradable polymeric materials are utilized as a cell scaffold in tissue engineering. A plasma technique can easily be used to introduce desired functional groups or chains onto the surface of materials, so it has a special application in improving the cell affinity of scaffolds.

The copolymer, poly(3-hydroxybutyric acidco-3-hydroxyvaleric acid) (PHBV) has been intensely studied as a tissue engineering substrate. Plasma treatment of PHBV films increases the nano roughness pattern and results in a moderate hydrophilicity on the film surface. This physicochemical change modifies the behaviour of the vero cells by stimulating cell adhesion, cell growth and spreading, etc. (Lucchesi et al. 2008). Poly(methylmethacrylate) films were modified by the application of glow discharge oxygen plasma. An increase in the hydrophilicity and surface free energy and an increase in the plasma power and application time was observed. This improves the surface properties of the implants (at the molecular level) in order to enhance the cell attachment to the materials (Ozcan et al. 2008).

Plasma treatment with acrylic acid is an attractive way of introducing carboxylic groups to a polyurethane (PU) surface and subsequently of immobilizing natural or synthetic molecules carrying amino groups in their structure, through the formation of amide bonds. The plasma treatment allows a monolayer of PAA, which is then functionalized with a biomacromolecule. The PU treated with macromolecules is a good candidate as a cell substrate. In particular, functionalization with poly (L-lysine) performs extremely well in the activation of cellular processes and shows optimum cell proliferation with increasing time (Sartori et al. 2008). A variety of extracellular matrix protein components such as gelatin, collagen, laminin and fibronectin could be immobilized onto the plasma treated surface 
to enhance cellular adhesion and proliferation. Electrospun nanofibres composed of polyglycolic acid, poly-L-lactic acid or poly(lactic-co-glycolic acid) were modified with carboxylic acid groups through plasma glow discharge with oxygen and gas phased acrylic acid. Such hydrophilized nanofibres were shown to enhance fibroblast adhesion and proliferation without compromising physical and mechanical bulk properties (Yool et al. 2009). Starch based scaffolds treated by argon plasma were shown to be a good support when used in bone tissue engineering. Higher proliferation rates, because of the novel protein surface interaction by plasma treatment were observed on the scaffolds (Santos et al. 2009).

\section{CONCLUSION}

Modern plasma tools employed in medical treatments are found to be more efficient and flexible in use. The plasma sterilization of both living and non-living objects offers non destructive removal of the microorganisms in a shorter treatment time. The use of different types of plasma jets in dentistry offers a painless treatment for the cleaning of dental cavities. The incorporation of the antimicrobial agents to plasma treated polymeric and metallic material enhances superior antimicrobial activity which significantly increases the convenience of these objects in medicine. Surface functionalization of artificial biomaterials (implants and scaffolds) by plasma treatment illustrates an improved rate of drug loading and controlled release even long term. This surface modification technique helps the introduction of bioactive species on the scaffolds, and promotes cell adhesion and proliferation which play an important role in tissue development. Thus the plasma treatment of materials represents an unusually convenient and versatile technique for surface activation and functionalization, which creates unique surface properties, often not obtainable by other methods. Plasma applications and plasma modified materials in medicine are undergoing fast development and plasma-medicine is becoming an important part of modern health care.

\section{ACKNOWLEDGEMENT}

Financial aid from the research grant of the Academy of Science of the Czech Republic (Project KAN 101630651), project MSM0021622411 and LC 06035 are greatly acknowledged.

\section{REFERENCES}

Aumsuwan N, McConnell MS, Urban MW: Tunable antimicrobial polypropylene surfaces: Simultaneous attachment of penicillin $(\mathrm{Gram}+)$ and gentamicin (Gram -). Biomacromolecules 10:623-629, 2009.

Bačáková L, Filová E, Rypáček F, Švorčík V, Starý $\mathrm{V}$ : Cell adhesion on artificial materials for tissue engineering. Physiol Res 53(Suppl. 1):S35-S45, 2004.

Bogaerts A, Neyts E, Gijbels R, Mullen J: Gas discharge plasmas and their applications: Review. Spectrochim Acta Part B 57:609-658, 2002.

Braithwaite NSJ: Introduction to gas discharges. Plasma Sources Sci Technol 9:517-527, 2000.

Canal C, Gaboriau F, Vílchez A, Erra P, Celma MG, Esquena J: Topographical and wettability effects of post-discharge plasma treatments on macroporous polystyrene-divinylbenzene solid foams. Plasma Process Polym 6:686-692, 2009.

Chen G, Zhou M, Chen S, Guohua L, Yao J: Nanolayer biofilm coated on magnetic nanoparticles by using a dielectric barrier discharge glow plasma fluidized bed for immobilizing an antimicrobial peptide. Nanotechnology 20:465706, 2009a.

Chen Y, Zheng X, Xie Y, Ji H, Chuanxian D: Antibacterial properties of vacuum plasma sprayed titanium coatings after chemical treatment. Surf Coat Technol 204:685-690, $2009 b$.

Chu PK, Chen JY, Wang LP, Huang N: Plasma-surface modification of biomaterials. Mater Sci Eng R Rep 36:143-206, 2002.

Conrads H, Schmidt M: Plasma generation and plasma sources. Plasma Sources Sci Technol 9:441-454, 2000.

Conte A, Buonocore GG, Sinigaglia M, Lopez LC, Favia P, Agostino R, Del Nobile MA: Antimicrobial activity of immobilized lysozyme on plasma-treated polyethylene films. J Food Prot 71:119-125, 2008.

Crow S, Smith JH: Gas plasma sterilization: Application of space-age technology. Infect Control Hosp Epidemiol 16:483-487, 1995.

Daniel A, Pen LC, Archambeau C, Reniers F: Use of a PECVD-PVD process for the deposition of copper containing organosilicon thin films on steel. Appl Surf Sci 256:82-85, 2009.

Denes FS, Manolache S: Macromolecular plasma-chemistry: An emerging field of polymer science. Prog Polym Sci 29:815-885, 2004.

Desmet T, Morent R, Geyter N, Leys C, Schacht E, Dubruel P: Nonthermal plasma technology as a versatile strategy for polymeric biomaterials 
surface modification: A Review. Biomacromolecules 10:2351-2378, 2009.

Eisenbrey JR, Hsu J, Wheatley MA: Plasma sterilization of poly lactic acid ultrasound contrast agents: surface modification and implications for drug delivery. Ultrasound Med Biol 35:1854-1862, 2009.

Favia P, Sardella E, Lopez L, Laera S, Milella A, Pistillo B, Intranuovo F, Nardulli M, Gristina R, D’Agostino R: Plasma assisted surface modification processes for biomedical materials and devices. NATO ASI Ser A 10:203-225, 2008.

Fridman G, Peddinghaus M, Ayan H, Fridman A, Balasubramanian $\mathrm{M}$, Gutsol A, Brooks A, Friedman G: Blood coagulation and living tissue sterilization by floating-electrode dielectric barrier discharge in air. Plasma Chem Plasma Process 26:425-442, 2006.

Fridman G, Brooks AD, Balasubramanian M, Fridman A, Gutsol A, Vasilets VN, Ayan H, Friedman G: Comparison of direct and indirect effects of non-thermal atmospheric-pressure plasma on bacteria. Plasma Process Polym 4:370-375, 2007.

Fridman G, Friedman G, Gutsol A, Shekhter AB, Vasilets VN, Fridman A: Applied plasma medicine. Plasma Process Polym 5:503-533, 2008.

Gaunt LF, Beggs CB, Georghiou GE: Bactericidal action of the reactive species produced by gas-discharge nonthermal plasma at atmospheric pressure: A review. IEEE Trans Plasma Sci 34:1257-1269, 2006.

Gomathi N, Sureshkumar A, Neogi S: RF plasma-treated polymers for biomedical applications. Curr Sci 94:1478-1486, 2008.

Goree J, Liu B, Drake D, Stoffels E: Killing of S. mutans bacteria using a plasma needle at atmospheric pressure. IEEE Trans Plasma Sci 34:1317-1324, 2006.

Griffiths N: Low-temperature sterilization using gas plasmas. Med Device Technol 4:37-40, 1993.

Gupta G, Anjum N: Plasma and radiation-induced graft modification of polymers for biomedical applications. Adv Polym Sci 162:35-61, 2003.

Gweon B, Kim DB, Moon SY, Choe W: Escherichia coli deactivation study controlling the atmospheric pressure plasma discharge conditions. Curr Appl Phys 9:625-628, 2009.

Halfmann H, Bibinov N, Wunderlich J, Awakowicz P: A double inductively coupled plasma for sterilization of medical devices. J Phys D Appl Phys 40:4145-4154, 2007.

Hayashi N, Guan W, Tsutsui S, Tomari T, Hanada Y: Sterilization of medical equipment using radicals produced by oxygen/water vapor RF plasma. Jpn J Appl Phys 10B 45:8358-8363, 2006.

Herrmann HW, Henins I, Park J and Selwyn GS: Decontamination of chemical and biological warfare agents using an atmospheric pressure plasma jet. Phys Plasmas 6:2284-2289, 1999.

Ji J, Zhang W: Bacterial behaviors on polymer surfaces with organic and inorganic antimicrobial compounds. J Biomed Mater Res Part A 10:448-453, 2007.

Jiang C, Chen MT, Gorur A, Schaudinn C, Jaramillo DE, Costerton JW, Sedghizadeh PP, Vernier PT, Gundersen MA: Nanosecond pulsed plasma dental probe. Plasma Process Polym 6:479-483, 2009.

Kim JS, Kuk E, Yu KN, Kim JH, Park SJ, Lee HJ, Kim SH, Park YK, Park YH, Hwang CY, Kim YK, Lee YS, Jeong DH, Cho MH: Antimicrobial effects of silver nanoparticles. Nanomed Nanotechnol Biol Med 3:95-101, 2007.

Klíma M, Janča J, Kapička V, Slavíček P, Saul P: Způsob vytváření fyzikálně a chemicky aktivního prostředí plazmovou tryskou a plazmová tryska. Patent CZ 147698, 12. 5. 1998.

Klíma M, Janča J, Kapička V, Slavíček P, Saul P: The method of making a physically and chemically active environment by means of a plasma jet and the related plasma jet. Patent US 6, 525, 481, 2003; Patent EP 1077021, 2005. Prior 12. 5. 1998 .

Kylián O, Rauscher H, Gilliland D, Bretagnol F, Rossi F: Removal of model proteins by means of low-pressure inductively coupled plasma discharge. J Phys D Appl Phys 41:095201, 2008.

Laroussi M: Low lemperature plasma-based sterilization: Overview and state-of-the-art. Plasma Process Polym 2:391-400, 2005.

Laroussi M: The biomedical application of plasma: A brief history of the development of a new field of research. IEEE Trans Plasma Sci 36:1612-1614, 2008.

Laroussi M, Tendero C, Lu X, Alla S, Hynes WL: Inactivation of bacteria by the plasma pencil. Plasma Process Polym 3:470-473, 2006.

Laroussi M, Hynes W, Akan T, Lu X, Tendero C: The plasma pencil: A Source of hypersonic cold plasma bullets for biomedical applications. IEEE Trans Plasma Sci 36:1298-1299, 2008.

Lee HW, Kim GJ, Kim JM, Park JK, Lee JK, Kim GC: Tooth bleaching with nonthermal atmospheric pressure plasma. J Endod 35:587-591, 2009.

Lerouge S, Wertheimer MR, Yahia LH: Plasma sterilization: A review of parameters, 
mechanisms, and limitations. Plasmas Polym 6:175-188, 2001.

Li B, Liua X, Menga F, Chang J, Dinga C: Preparation and antibacterial properties of plasma sprayed nano-titania/silver coatings. Mater Chem Phys 118:99-104, 2009.

Lin SM, Swanzy, Jacobs PT: Method of hydrogen peroxide plasma sterilization. U S patent 5876 666, 1999.

Losic D, Cole MA, Dollmann B, Vasilev K, Griesser HJ: Surface modification of nanoporous alumina membranes by plasma polymerization. Nanotechnology 19:245704, 2008.

Lu X, Cao Y, Yang P, Xiong Q, Xiong Z, Xian Y, Pan Y: An RC plasma device for sterilization of root canal of teeth. IEEE Trans Plasma Sci 37:668-6732009.

Lucchesi C, Ferreira BMP, Duek EAR, Santos AR Jr., Joazeiro PP: Increased response of vero cells to PHBV matrices treated by plasma. J Mater Sci Mater Med 19:635-643, 2008.

Martines E, Zuin M, Cavazzana R, Gazza E, Serianni G, Spagnolo S, Spolaore M, Leonardi A, Deligianni V, Brun P, Aragona M, Castagliuolo I, Brun P: A novel plasma source for sterilization of living tissues. New J Phys 11:115014, 2009.

Miao H, Jierong C: Inactivation of Escherichia coli and properties of medical poly(vinyl chloride) in remote-oxygen plasma. Appl Surf Sci 255:5690-5697, 2009.

Miola M, Ferraris S, Nunzio SD, Robotti PF, Bianchi G, Fucale G, Maina G, Cannas M, Gatti S, Massé A, Brovarone CV, Verne E: Surface silver-doping of biocompatible glasses to induce antibacterial properties. Part II: Plasma sprayed glass-coatings. J Mater Sci Mater Med 20:741-749, 2009.

Montie C, Kelly WK, Roth R: Overview of research using the one-atmosphere uniform glow discharge plasma for sterilization of surfaces and materials. IEEE Trans Plasma Sci 28:41-50, 2000.

Moon Y, Kim DB, Gweon B, Choe W, Song HP, Jo $\mathrm{C}$ : Feasibility study of the sterilization of pork and human skin surfaces by atmospheric pressure plasmas. Thin Solid Films 517:4272-4275, 2009.

Moreau M, Orange N, Feuilloley MGJ: Non-thermal plasma technologies: New tools for bio-decontamination. Biotechnol Adv 26:610-617, 2008.

Nie QY, Cao, Ren CS, Wang DZ, Kong MG: A two-dimensional cold atmospheric plasma jet array for uniform treatment of large-area surfaces for plasma medicine. New J Phys 11:115015, 2009.

Noyce JO, Michels H, Keevil CW: Potential use of copper surfaces to reduce survival of epidemic methicillin-resistant Staphylococcus aureus in the healthcare environment. J Hosp Infect 63:289297, 2006.

Oehr C: Plasma surface modification of polymers for biomedical use. Nucl Instrum Methods Phys Res B 208:40-47, 2003.

Ozcan C, Zorlutuna P, Hasirci V, Hasirci N: Influence of oxygen plasma modification on surface free energy of PMMA films and cell attachment. Macromol Symp 269:128-137, 2008.

Panyala NR, Peña-Méndez EM, Havel J: Silver or silver nanoparticles: A hazardous threat to the environment and human health? J Appl Biomed 6:117-129, 2008.

Rai M, Yadav A, Gade A: Silver nanoparticles as a new generation of antimicrobials. Biotechnol Adv 27:76-83, 2009.

Ruparelia JP, Chatterjee AK, Duttagupta SP, Mukherji S: Strain specificity in antimicrobial activity of silver and copper nanoparticles. Acta Biomater 4:707-716, 2008.

Santos MI, Pashkuleva I, Alves CM, Gomes ME, Fuchs S, Unger RE, Reisab RL, Kirkpatrick CJ: Surface-modified 3D starch-based scaffold for improved endothelialization for bone tissue engineering. Mater Chem 19:4091-4101, 2009.

Sartori S, Rechichi A, Vozzi G, D'Acunto M, Heine E, Giusti P, Ciardelli G: Surface modification of a synthetic polyurethane by plasma glow discharge: Preparation and characterization of bioactive monolayers. React Funct Polym 68:809-821, 2008.

Sharma VK, Yngard RA, Lin Y: Silver nanoparticles: Green synthesis and their antimicrobial activities. Adv Colloid Interface Sci 145:83-96, 2009.

Shenton MJ, Stevens GC: Surface modification of polymer surfaces: Atmospheric plasma versus vacuum plasma treatments. J Phys D Appl Phys 34:2761-2768, 2001.

Shinonaga Y, Arita K: Surface modification of stainless steel by plasma-based fluorine and silver dual ion implantation and deposition. Dent Mater 28:735-742, 2009.

Silver S, Phung LT: Bacterial heavy metal resistance: New surprises. Annu Rev Microbiol 89:753-789, 1996.

Sladek REJ, Stoffels E, Walraven R, Tielbeek PJA, Koolhoven RA: Plasma treatment of dental cavities: A feasibility study. IEEE Trans Plasma Sci 32:1540-1543, 2004.

Sodhi RNS, Sahi VP, Mittelman MW: Application of electron spectroscopy and surface modification techniques in the development of anti-microbial coatings for medical devices. J Electron Spectros Relat Phenomena 121:249-264, 2001. 
Sohbatzadeh F, Colagar AH, Mirzanejhad S, Mahmodi S: E. coli, P. aeruginosa, and B. cereus bacteria sterilization using afterglow of non-thermal plasma at atmospheric pressure. Appl Biochem Biotechnol 160:1978-1984, 2009.

Tendero C, Tixier C, Tristant P, Desmaison J, Leprince P: Atmospheric pressure plasmas: A review. Spectrochim Acta Part B 61:2-30, 2006.

Trompeter FJ, Neff WJ, Franken O, Heise M, Neiger M, Shuhai L: Reduction of Bacillus subtilis and Aspergillus niger spores using nonthermal atmospheric gas discharges. IEEE Trans Plasma Sci 30:1416-1423, 2002.

Vasilev K, Poh Z, Kant K, Chan J, Michelmore A, Losic D: Tailoring the surface functionalities of titania nanotube arrays. Biomaterials 31:532-540, 2010.
Weir E, Lawlor A, Whelan A, Regan F: The use of nanoparticles in anti-microbial materials and their characterization. Analyst 133:835-845, 2008.

Xingmin S, Yukang Y, Yanzhou S, Wang Y, Fengling P, Yuchang Q: Experimental research of inactivation effect of low-temperature plasma on bacteria. Plasma Sci Technol 8:569-572, 2006.

Yool HS, Kim TG, Park TG: Surface-functionalized electrospun nanofibers for tissue engineering and drug delivery. Adv Drug Delivery Rev 61:1033-1042, 2009.

Zhang W, Zhang Y, Ji J, Yan Q, Huang A, Chu PK: Antimicrobial polyethylene with controlled copper release. J Biomed Mater Res Part A 83:838-844, 2007.

Zhang X, Huang J, Liu X, Peng L, Guo L, Lv G, Chen W, Feng K, Yang S: Treatment of Streptococcus mutans bacteria by a plasma needle. J Appl Phys 105:1063, 2009. 